\title{
Cumprindo pena juntos
}

\author{
Thais Lemos Duarte' (iD) 0000-0002-9149-7387 \\ Luana Hordones Chaves' (iD) 0000-0003-4301-3357 \\ Isabela Cristina Alves de Araújo' (iD) 0000-0002-2526-4825
}

Universidade Federal de Minas Gerais, Programa de Pós-Graduação em Sociologia, Belo Horizonte, MG, Brasil. 31270-901 - ppgs@fafich.ufmg.br

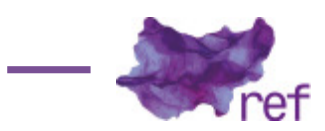

Resumo: O artigo pretende analisar a perspectiva de mulheres companheiras de presos no estado do Rio de Janeiro sobre os papéis que elas desempenham nas prisões. Partimos da hipótese de que suas ações teriam uma relação direta com a divisão sexual do trabalho, ou seja, as mulheres desempenhariam atividades relacionadas ao cuidado doméstico e afetivo em relação a seus parceiros, ainda que estes estejam privados de liberdade. Assim, sofreriam processos típicos do mundo prisional, como o controle dos corpos e a imposição de regras. Porém, os dados demonstram que são vários os papéis desempenhados por mulheres que optam por 'cumprir pena junto' com companheiros encarcerados, não podendo reduzir suas ações a uma relação de subordinação de gênero. Ainda que assumam o papel do cuidado e de apoio durante a privação de liberdade, elas exercem funções adicionais, percebidas como emancipatórias e constituidoras de novas identidades.

Palavras-chove: sistema prisional; companheiras de presos; divisão sexual do trabalho; papéis de gênero.

\section{Serving Sentence Together}

Abstract: The article intends to analyze the perspective of lifemates of prisoners of the Rio de Janeiro state penitentiary system, about their roles in the prison structure. We assumed that their actions would have a direct relation with the sexual division of labor. In other words, women would perform activities related to domestic and affective care in relation to their partners, even though they are arrested. Thus, they would suffer the typical processes of the prison world, such as the control of bodies and the imposition of rules. However, the data show that there are several roles performed by women who choose to 'serve sentence together' with their convicted partner, thus, it is not possible to reduce their actions in a gender subordination relationship. Even if they take on the role of care and support during deprivation of liberty, they perform additional functions, perceived as emancipatory and constituent of new identities.

Key words: Prison system; Prisoners' lifemates; Sexual division of labor; Gender roles.

\section{Introdução}

Este artigo visa analisar as perspectivas de indivíduos quase imperceptíveis aos grupos sociais: as companheiras de pessoas presas. O exercício de se atentar a elas busca, em alguma medida, projetar um olhar diferente do normalmente fixado ao sistema prisional. Os estudos sobre prisões, tanto os clássicos quanto os mais recentes, apresentam geralmente como objeto as pessoas privadas de liberdade, haja vista, sobretudo, as condições de encarceramento e as flagrantes violações ocorridas nos cárceres nacionais (Antônio L. PAIXÃO, 1987; Carlos A. T. MAGALHÃES, 2006; Augusto THOMPSON, 1993; Julita LEMGRUBER, 1999).

Entretanto, importa estudar as parceiras dos presos, entre outras razões, porque elas exercem articulações significativas entre o mundo prisional e a vida além-muros. Constituem também uma mediação que permite superar a distância entre o cárcere e o mundo exterior, tornando-se espécies 
de "vasos comunicantes" (Rafael GODOI, 201 1). Impossibilitadas de trazer os presos para casa, as mulheres tentam levar o lar até os custodiados através da transferência de atividades íntimas para dentro dos muros da cadeia. Esses estabelecimentos se desdobram, muitas vezes, em "satélites domésticos", cabendo às pessoas do sexo feminino a tarefa de cuidar de um ente querido preso (Megan COMFORT, 2002).

Apesar do papel fundamental que essas mulheres exercem não apenas para seus parceiros encarcerados, mas para a própria estrutura prisional, poucas pesquisas acadêmicas se atentaram à temática. Quando são abordadas, as companheiras dos presos aparecem na literatura de duas formas: de um lado, os trabalhos abordam suas vivências de forma tangencial, mais centrada em aspectos familiares como um todo (Ana Caroline M. G. JARDIM, 2010; Claudia KUHN, 2016; AnneMarie DEVREUX, 2009); de outro, e como foco deste trabalho, as companheiras são a centralidade do estudo (Jacqueline S. F. LIMA, 2013; Giane SILVESTRE, 2012; Manuela Ivone CUNHA, 2003).

Como exemplo de estudo com esse segundo mote, objetivando compreender as implicações da política de encarceramento em massa em São Paulo, Silvestre (2012) observou os efeitos da presença de familiares de presos, sobretudo, das companheiras, nas relações estabelecidas em Itirapina, município do interior do estado de São Paulo, fortemente pautado pela presença de estabelecimentos penais. Observou-se, na referida pesquisa, que esses atores são submetidos constantemente ao controle social exercido tanto formalmente pelas instituições carcerárias quanto informalmente pelos moradores da cidade. Em geral, eles são analisados como 'criminosos em potencial', especialmente pelos habitantes locais, ainda que os mesmos valores morais sejam compartilhados por ambos.

Cunha $(2003,2014)$, por sua vez, observou o modo como a reclusão afeta e molda as famílias, parceiras e comunidades de proveniência dos custodiados portugueses. Aproximando mais a lente daqueles que rodeiam os presos além-muros, a pesquisadora evidenciou uma experiência carcerária alargada que inclui, por um lado, os desafios e dificuldades - financeiras, sociais, emocionais - enfrentadas pelas famílias e parceiras de presos durante a privação de liberdade e, por outro, o apoio material, moral e emocional que esses atores prestam aos presos. Adotando uma abordagem sobretudo etnográfica, Cunha (2014) trabalhou com a ideia de que a reclusão desorganiza ou desfaz, invariavelmente, laços interpessoais, bem como mostra ser demasiado simplista uma análise em termos de meros ganhos e perdas para familiares ou presos.

Com linha analítica similar, estudando o contexto norte-americano, Comfort $(2002,2003$, 2007) se atentou para a importância das companheiras no contexto penal e desenvolveu uma agenda de pesquisa centrada nos impactos que a prisão traz, não apenas para as famílias de presos, mas principalmente para as mulheres que possuem alguma relação afetiva com os custodiados. Segundo a autora, as mulheres de pessoas presas vivenciam no contato com a instituição prisional a chamada "prisionização secundária", pois basicamente decidem, de alguma forma, "cumprir pena junto" de seus companheiros privados de liberdade. Tornam-se, então, sujeitas às regras institucionais e modificam suas dinâmicas familiares ao estabelecerem uma rotina de idas periódicas às prisões. Assim, baseando-se em Comfort $(2002,2003,2007), 0$ que chamamos de 'cumprir pena junto' diz respeito portanto à presença constante nos dias de visita, à adesão de uma forma de vida condicionada pela instituição prisional e prestação de cuidados fundamentais para amenizar as privações estipuladas aos presos.

Fundamentando-se nas reflexões já propostas sobre companheiras de presos, este artigo busca analisar a perspectiva dessas mulheres sobre os papéis que desempenham nos cárceres do estado do Rio de Janeiro. Interessa, aqui, entender de que maneira elas vivenciam o que Comfort (2003) denomina de "prisionização secundária" e quais são os processos sociais envolvidos para que essas mulheres se tornem "satélites domésticos" no ambiente carcerário. A fim de atingir esses objetivos, cabe considerar algumas discussões teóricas sobre os papéis tradicionalmente desempenhados pelas mulheres no meio social, de modo que, além do debate empírico, serão abrangidas neste artigo algumas reflexões proferidas em estudos sobre gênero e, por sua vez, sobre divisão sexual do trabalho.

\section{Gênero e divisão sexual do trabalho}

Conforme Joan Scott (1995), 'gênero' é uma categoria geralmente utilizada para se referir à organização social baseada na relação entre os sexos, e as expectativas dos comportamentos dos indivíduos costumam ser definidas cultural e socialmente a partir de diferenças biológicas. Não à toa, os anseios em relação às mulheres e aos homens são diferentes, tendo em vista as suas distinções naturais. Espera-se que aquelas que possuem o sexo feminino tenham uma essência passiva, submissa e devotada, enquanto a liderança, a autoridade e a postura de provedor sejam características esperadas de indivíduos homens. Esse tipo de percepção ultrapassa qualquer noção de complementaridade e, como Heleieth Saffioti (2004) propõe, demarca uma relação de poder em que as mulheres estão em uma posição desprivilegiada em comparação aos homens. 
Tal como em alguma medida ocorre em outros tipos de relações sociais - como aquelas pautadas por questões de classe, etnia e raça -, as interações entre homens e mulheres se fundamentam, pois, em uma assimetria de poder e dominação. Ao abordar a agência da mulher em uma relação afetiva ou familiar é preciso considerar, antes de tudo, que a sociedade utiliza a ideologia naturalista, tanto para relegar o gênero ao sexo biológico quanto para reduzir as práticas a papéis sociais definidos sexualmente. Por conseguinte, as situações em que os homens e as mulheres vivenciam, bem como as configurações dos casais e das famílias devem ser lidas como construções sociais (Danièle KERGOAT, 2009), ou seja, não são naturais, já que são expressões das relações sociais de sexo configuradas por um sistema patriarcal. Ao mesmo tempo, essas constituições perfazem espaços de interação social que vão, por sua vez, recriando o social e dinamizando o processo de sexuação do social - que se exprime também no campo do trabalho (KERGOAT, 2009).

Essa percepção vai ao encontro de alguns estudos de antropólogas feministas que cunharam a categoria analítica "divisão sexual do trabalho", indo além do proposto por Lévi-Strauss com o termo "divisão do trabalho". Enquanto este antropólogo argumentava que havia uma complementaridade nas tarefas exercidas entre homens e mulheres, as feministas defenderam existir uma relação de poder resultante das desigualdades de gênero (Helena HIRATA; KERGOAT, 2007; KERGOAT, 2009).

Nesse mote, Hirata e Kergoat (2007) afirmam ser preciso relacionar as desigualdades sistemáticas aos processos utilizados pela sociedade para hierarquizar o trabalho social, criando um sistema de gênero. Designa-se aos homens a esfera produtiva, de maior valor social, enquanto que às mulheres cabe o âmbito reprodutivo, voltado ao cuidado do outro. Ou seja, histórica e culturalmente, especialmente dentro da sociedade capitalista, sempre coube à mulher a responsabilidade pelos cuidados com a casa e com a família, independentemente de sua idade, condição de ocupação e nível de renda. O trabalho doméstico recaía sobre as mulheres com base no discurso - vivo até hoje - da naturalidade feminina para o cuidado. Essa atribuição social do cuidado ao feminino, primeiramente, limitou a vida das mulheres ao espaço privado e, posteriormente, com as transformações socioeconômicas e a busca de independência feminina, marcou desvantagens em relação aos homens na atuação econômica e social (SOUZA; GUEDES, 2016).

Baseada, pois, em dois princípios organizadores, o da separação e o da hierarquia, a divisão sexual do trabalho "[...] é a forma de divisão do trabalho social decorrente das relações sociais entre os sexos; mais do que isso, é um fator prioritário para a sobrevivência da relação social entre os sexos" (HIRATA; KERGOAT, 2007, p. 599). Em outras palavras, embora seja historicamente tida como 'natural', a demarcação diferenciada das atividades voltadas aos homens e às mulheres é fruto de uma relação de dominação existente entre ambos. Essa interação impõe limites, sujeição e servidão ao submetido, conferindo uma dessimetria estrutural que é concomitantemente o efeito e o alicerce da dominação (Erika APFELBAUM, 2009).

Guiada por esse referencial teórico, a análise em tela parte da hipótese de que o papel das companheiras de presos guardaria uma relação direta com a divisão sexual do trabalho dominante no meio social. Essas mulheres manteriam o exercício do cuidado doméstico e afetivo em relação aos seus parceiros privados de liberdade e, de fato, sofreriam processos típicos do mundo prisional que tradicionalmente incidem sobre os custodiados, como o controle dos corpos e a imposição de regras, muitas extralegais, se não ilegais. Por outro lado, para além de testar essa hipótese, o artigo também se propõe a compreender outras potenciais funções atinentes às mulheres no mundo carcerário, buscando responder a seguinte questão: esses atores exerceriam tarefas e desempenhariam papéis na vida carcerária diferentes daqueles comumente estabelecidos nas relações de gênero e, por sua vez, na divisão sexual do trabalho?

\section{Metodologia}

Os dados aqui utilizados são de natureza qualitativa, coletados durante a pesquisa de doutorado que ensejou a tese denominada Amor em cárcere: relações afetivas no sistema penitenciário do Rio de Janeiro (Thais DUARTE, 2015)². Foram traçadas duas estratégias de campo para este estudo. Em primeiro lugar, foram acionadas mulheres via organizações destinadas a egressos do sistema prisional fluminense. Alguns familiares de presos costumam estabelecer vínculos com esses espaços, o que facilitou, então, a realização de entrevistas semiestruturadas nessa fase

\footnotetext{
${ }^{1}$ A divisão sexual do trabalho foi objeto de pesquisa em diversos países, mas foi na França, no início dos anos 1970 , que as bases teóricas desse conceito se consolidaram, sob o impulso do movimento feminista. O paradigma da divisão sexual do trabalho fortaleceu o debate sobre o trabalho da mulher nos espaços público e privado, tirando da invisibilidade a reprodução social executada gratuitamente pelas mulheres (Luana P. SOUZA; Dyego R. GUEDES, 2016).

2 Desenvolvida no âmbito do Programa de Pós-Graduação em Ciências Sociais da Universidade do Estado do Rio de Janeiro, sob orientação do professor João Trajano Sento-Sé.
} 
da pesquisa. De fato, poder abarcar mulheres cujos companheiros haviam recém-saído do sistema prisional possibilitou o acesso a indivíduos com uma vivência relativa a todo o período de encarceramento do familiar, desde o início até o término do aprisionamento, captando diferentes fases do contato da pessoa com o sistema de justiça criminal e apreendendo, assim, os efeitos deletérios da privação de liberdade na vida doméstica.

Em segundo lugar, o campo se desenvolveu através do contato com as visitantes de presos no portão central do Complexo de Gericinó, na cidade do Rio de Janeiro. Esse local é composto por 26 unidades prisionais, englobando estabelecimentos de naturezas distintas ${ }^{3}$. Nesse momento, foram realizadas apenas conversas informais com diversas mulheres. Isso porque Gericinó é quase sempre muito tumultuado, com cerca de dois mil visitantes por dia. E, como o foco das mulheres no lugar é, sobretudo, entrar na unidade prisional, muitas deixam de estabelecer conversas ou relações mais duradouras para evitar atrasos no encontro com o parente preso. Por isso, optou-se por apenas manter um contato mais superficial com as famílias nesse espaço, com a expectativa central de compreender como eram formadas as filas em frente ao complexo penitenciário e analisar a dinâmica de visitação nas unidades prisionais abrangidas na área.

As seções seguintes apresentam as informações coletadas por ambas as vias de trabalho de campo. Inicialmente, é feita uma descrição sobre como as visitas às prisões fluminenses são operacionalizadas. Em seguida, são analisadas as narrativas femininas sobre suas idas aos cárceres estaduais e suas relações afetivas com os companheiros privados de liberdade, com vistas a compreender como essas mulheres percebem os papéis que desenvolvem no âmbito prisional.

\section{Dinâmicas de visitação nas prisões fluminenses}

Conforme normas estipuladas pela Secretaria de Estado de Administração Penitenciária do Rio de Janeiro (SEAP), todos os presos estão habilitados a receber visitas comuns. Desde que devidamente credenciados, podem ir ao cárcere cônjuges, companheiros(as), filhos(as), enteados(as), mães, pais, irmãos(ãs), avôs(ós), netos(as), tios(as), sobrinhos(as), bem como madrasta e padrasto, no caso de não haver genitores cadastrados. Adicionalmente, apenas uma pessoa pode se cadastrar como amigo(a) do preso, mediante a devida comprovação de amizade através de declaração por instrumento público de duas testemunhas, com firma reconhecida em cartório. Isto é, o modelo de família proposto pela SEAP é pouco flexível, uma vez que são respeitadas basicamente as relações de parentesco e, portanto, ignoradas possíveis novas configurações familiares.

Já a visita íntima é concedida ao preso - tanto condenado, quanto provisório - e sua companheira, desde que comprovada a relação marital ou de união estável através de escritura declaratória exarada em cartório. De igual maneira, as visitas homoafetivas também são autorizadas no estado, bem como a realização de visitas entre cônjuges presos. De tempos em tempos, com uma periodicidade definida pelas direções das unidades prisionais, uma mulher privada de liberdade pode realizar encontros íntimos no local onde seu companheiro se encontra preso.

A legislação brasileira e a do Rio de Janeiro são ambíguas em relação à natureza jurídica da visita íntima. Determinadas normas indicam que esse tipo de visitação constitui um direito do preso, como a Resolução n 4/201 1 do Conselho Nacional de Política Nacional e Penitenciária (CNPCP), a qual dispõe que esse tipo de visitação é uma garantia do preso, recomendando que as administrações prisionais assegurem o acesso da prática a todas as pessoas custodiadas (BRASIL, 2011 ). Por outro lado, outras normas estipulam essa visita como uma regalia. De fato, na prática, os encontros íntimos no sistema penitenciário do Rio de Janeiro - e em outras unidades da federação - são realizados por presos considerados pela administração prisional como de 'bom comportamento', e é concedida a autorização para visita íntima como uma espécie de benefício. Não está prescrito em norma alguma, porém, o efetivo significado desse termo, o que deixa a avaliação sobre a conduta do preso, em boa medida, nas mãos dos servidores. Justamente por abrir espaço a ações discricionárias, a visita íntima pode ser constantemente barganhada (DUARTE, 2015).

As visitas às unidades prisionais estaduais são autorizadas através de apresentação de uma carteira emitida pela SEAP que, formalmente, demora aproximadamente 30 dias para ser confeccionada. Nesse ínterim, os familiares não podem visitar seus parentes privados de liberdade, a não ser que consigam uma autorização da assistência social da SEAP para a realização de um encontro excepcional. Por certo, são as direções dos estabelecimentos carcerários que estipulam os dias e horários voltados à realização das visitas. Normalmente, um dia da semana é destinado às visitas comuns, ao passo que outro às íntimas. No dia do encontro sexual, o preso não pode receber outro tipo de visitante, como, entre outros, mãe e irmã.

Os dias de visita em uma unidade prisional fluminense costumam ser intensos. Como já mencionado em relação a Gericinó, os visitantes, especialmente mulheres, formam desde a madrugada uma longa fila em frente ao portão central do estabelecimento para esperar a liberação

\footnotetext{
${ }^{3}$ Disponível em: http://gmf.tjr.jus.br/unidades-prisionais. Acesso em 09/09/2020.
} 
para a visitação. Quando finalmente se inicia a entrada, as mulheres apresentam suas carteiras aos policiais com função de guarda nas portas das unidades e, em seguida, formam uma nova fila para aguardar a revista.

Até poucos anos atrás eram realizadas revistas vexatórias nos visitantes, sobretudo, em pessoas do sexo feminino, de modo que elas precisavam ficar nuas diante de agentes prisionais, agachar-se e realizar outros movimentos repetidamente, a fim de atestar que não carregavam qualquer objeto proibido, como drogas, celulares e armas em seus corpos. Entretanto, em 2018, pôs-se fim a esse tipo de procedimento no Rio de Janeiro 4 . A prática atual predominante nas entradas das unidades prisionais é submeter o visitante a uma inspeção através de um scanner corporal. A revista corporal é executada apenas em casos de 'fundada suspeita', se for detectado por vias tecnológicas indícios de que a pessoa carrega algum objeto proibido.

As visitas comuns costumam ser realizadas nos pátios das unidades prisionais, com duração de aproximadamente oito horas. Os presos e seus familiares passam o dia juntos, fazendo refeições trazidas pelos visitantes, as ditas 'sucatas'. Por sua vez, as visitas íntimas ocorrem em espaços específicos dos cárceres, os chamados 'parlatórios', que são formados por pequenas celas, compostas por uma cama de casal e um banheiro, para onde os presos e suas companheiras podem levar um ventilador e uma televisão. Tais locais apresentam forte rotatividade, já que o tempo de permanência está diretamente relacionado ao quantitativo de casais que realizará o encontro íntimo em um determinado dia.

Todas as práticas citadas acima constituem meios formais de realização dos encontros íntimos no cárcere. Há, porém, outras formas de manutenção de relações sexuais para além das visitas íntimas. No 'ratão', por exemplo, os casais utilizam espaços improvisados dos pátios das unidades prisionais para fazer sexo durante as visitas comuns. Há relatos de que a prática ocorre em um banheiro localizado em uma seção mais discreta do cárcere, em uma cela com fácil acesso ao pátio de visitas e, até mesmo, embaixo da mesa destinada às refeições dos presos e de seus familiares.

Um grupo de presos cobra uma quantia aos interessados em praticar o 'ratão'. Os valores variam entre dez, vinte ou trinta reais, dependendo do tempo destinado ao ato sexual. Por certo, a prática é amplamente conhecida pela administração prisional que inclusive a respeita e, em alguma medida, a controla, sendo possível apontar, pois, que o 'ratão' se constituiria como uma espécie de 'controle do descontrole'. Os agentes prisionais permitem a manutenção de algo que, a princípio, constituiria uma perda de gerenciamento das atividades do cárcere. Por sua vez, os presos sabem que os agentes conhecem o 'ratão', mas elaboram inúmeras formas, algumas bastante criativas, de burlar o controle institucional. $O$ 'ratão' poderia ser interpretado, então, como potente mecanismo de barganha entre a administração e o preso. Se efetivamente tivessem interesse, os agentes prisionais tomariam uma atitude eficaz para reprimir essa prática.

Tanto nos dias de visita íntima quanto nos de visita comum os familiares de presos, especialmente as companheiras, devem ainda se submeter a uma série de regras impostas pela administração prisional e pelos internos. A SEAP estipula o tipo de vestimenta a ser utilizado pelo visitante em suas idas às unidades prisionais: é vedado o uso de roupa transparente, curta, decotada e justa, bem como são proibidos sapatos de salto, bonés, óculos escuros, relógios, joias e bijuterias. A aliança seria o único adereço permitido às mulheres durante as visitas às unidades prisionais, símbolo que atestaria sua relação de conjugalidade com certo homem privado de liberdade.

Adicionalmente, os visitantes não podem usar peças de roupas ou acessórios da cor vermelha, tampouco azul marinho ou preta. As duas últimas cores se confundiriam com trajes utilizados por pessoas da administração prisional, ao passo que a primeira faria referência a uma facção criminal do Rio de Janeiro, o Comando Vermelho. Há, inclusive, diversos outros procedimentos a serem seguidos pelas companheiras de presos para não incitar as disputas entre os distintos grupos criminosos que dividem o sistema prisional estadual. Nesse sentido, em hipótese alguma as mulheres devem brigar entre si em decorrência dessas rivalidades, de modo que, nas filas de visitantes em que estariam misturadas pessoas pertencentes a diferentes facções, qualquer tipo de rixa deve ser evitada e qualquer provocação ignorada. Caso contrário, as visitas podem ser suspensas pela administração prisional, assim como o preso e o familiar envolvidos em alguma briga podem ser severamente punidos pelas pessoas privadas de liberdade, inclusive com morte.

Outras regras são impostas às mulheres visitantes. Por exemplo, elas não devem olhar diretamente nos olhos de presos que não pertençam a sua família, não devem falar alto, não devem questionar os procedimentos adotados por agentes prisionais nas entradas das unidades prisionais, não devem fazer amizade com pessoas da administração prisional e não devem fazer barulho durante os encontros íntimos. Essas regras em alguma medida recaem também aos presos, uma vez que eles não devem conversar com visitantes de outros custodiados, não podem encarar

${ }^{4}$ Lei estadual $n^{\circ} 7.010 / 2015$, a qual foi sujeita a uma série de disputas judiciais, tendo sido finalmente assegurada a sua constitucionalidade em 2018. Disponível em: https://gov-rj.jusbrasil.com.br/legislacao/191596255/lei-7010-15rio-de-janeiro-rj. Acesso em: 04/09/2020. 
diretamente as visitas de outras pessoas, não podem 'cantar' ou 'mexer' com as companheiras dos demais internos, devem manter os espaços dos parlatórios asseados e não podem falar palavrões, tampouco agredir suas companheiras publicamente. No que tange a essa última regra, a violência familiar chega a ser consentida por todos os atores do cárcere, tanto homens quanto mulheres e administração prisional, sob a condição de não afetar a rotina institucional. $O$ recurso à violência é, portanto, válido, desde que silencioso.

As regras impostas às mulheres nas dinâmicas de visitas de privados de liberdade seriam exemplos claros do já mencionado processo de "prisionização secundária" descrito por Comfort $(2002,2003,2007)$. De fato, esse conceito seria uma variação do proposto por Donald Clemmer (1950), que referencia as mudanças comportamentais e culturais derivadas do cumprimento da privação de liberdade. Comfort avança em relação a esse conceito e demonstra como as companheiras de presos, uma vez em contato com o ambiente prisional, são submetidas ao processo de prisionização que, apesar de se constituir como uma versão mais fraca, é eloquente na sujeição às regras e ao espaço institucional. Isto é, as visitantes de presos "[...] experimentam restrições de direitos, diminuição de recursos, marginalização social e outras consequências do confinamento penal, apesar de serem legalmente inocentes e residirem fora dos limites da prisão" (COMFORT, 2003, p. 78).

A prisionização estendida às visitantes exige adaptação às normas, bem como implica em uma vigilância e em uma limitação corporal. Por essa razão, os procedimentos de inspeção corporal e o controle das vestimentas tornam-se pontos centrais das dinâmicas de visitação nas prisões fluminenses. De igual maneira, para além da regulamentação dos corpos femininos, há uma desvalorização sistemática do tempo das visitantes pela instituição prisional. Não à toa, observam-se as longas filas nas portas dos cárceres e os demorados procedimentos a que as mulheres devem se submeter para entrar nesses estabelecimentos.

Esse tipo de análise converge com a vertente criminológica que observa as dores do aprisionamento (Gresham SYKES, 1999). Por um lado, a prisão gera falta de autonomia individual sobre o tempo e sobre a aparência naqueles que visitam pessoas privadas de liberdade e, por outro, produz uma dependência direta das normas e dos serviços destinados aos visitantes. Todos esses elementos deliberadamente administrados e controlados pela instituição prisional reforçam o sentimento de impotência e subserviência feminina em suas interações no cárcere (COMFORT, 2003). Tal análise é aprofundada e, em alguma medida, relativizada nas seções seguintes, que tratam, especificamente, das narrativas das mulheres de presos sobre suas experiências afetivas nas prisões do Rio de Janeiro.

\section{Afeto na prisão}

As perspectivas femininas sobre seus relacionamentos afetivos são permeadas por forte elemento emocional. Não raro, durante as entrevistas, as mulheres se valiam de sentimentos percebidos como estruturantes à relação com o companheiro preso, sobretudo, o 'amor'.

Eu acho que foi, assim, o gostar mais dele foi... Eu acho que foi quase no sentido da pena junto, sabe assim? De ter pena, sentir pena dele, de estar lá e eu, como esposa dele, eu tenho que ter uma obrigação de fazer alguma coisa por ele. E aquela coisa de gostei e 'ah, não, poxa, ele está ali preso, vou ficar com ele, vou ser fiel. (Companheira D).

Comfort (2007) trata dos mecanismos utilizados pelas mulheres para desenvolver e sustentar as relações separadas pelos muros da prisão. Os telefonemas, as cartas, as comidas e as visitas compõem alternativas para aliviar o isolamento e as privações a que esses casais estão submetidos, o que interfere sobremaneira na vida e na dinâmica doméstica das companheiras de presos.

No seu esforço de 'se juntarem ao' e apoiarem o ente amado, as mulheres relacionam o ambiente doméstico com a cela prisional, o que dá origem a uma série de sanções - estigma, censura, invasão de privacidade, regras, limitação espacial e fracionamento do tempo - que recaem sobre o lar. Desta forma, mesmo quando não estão fisicamente em San Quentin, as mulheres estão sujeitas à prisionização secundária por via da gestão e exploração institucionais, uma vez que os métodos para manter o contato com um parceiro obrigam a cedência da morada privada, que se torna um prolongamento do controle penal (COMFORT, 2007, p. 1.076).

Nesse sentido, as entrevistadas ressaltaram o momento de preparação para os dias de visita nas unidades prisionais como uma ocasião importante em suas rotinas semanais. Era comum, durante o trabalho de campo, ver inúmeras mulheres chegando ao Complexo de Gericinó, de manhã cedo, carregando bolsas de plástico abarrotadas de comida, doces, cigarros e refrigerantes, as já citadas 'sucatas'. Para além do amor, as entrevistadas demonstram que esse empenho em visitar e em levar a 'sucata' era justificada em parte por uma espécie de compaixão da mulher em relação ao seu companheiro em restrição de liberdade. As unidades prisionais costumam apresentar péssimas condições infraestruturais, o que comove as esposas dos presos que buscam, então, suprir certas carências materiais. 
É porque tem vezes que a pessoa chega lá só com a roupa do corpo e nas primeiras noites dorme no chão, porque ninguém conhece a pessoa que chegou e vai dando travesseiro e cobertor. [...] A polícia não vai chegar dando cobertor 'esse aqui é seu cobertorzinho, seu travesseirinho e a sua cama'. É cada um por si. (Companheira F).

Uma das mulheres entrevistadas relatou praticamente não dormir nas noites anteriores às visitas, porque passava grande parte da madrugada cozinhando alimentos que seriam oferecidos ao seu marido. Tais relatos corroboram a análise de Hirata e Kergoat (2007) sobre a invisibilidade do trabalho exercido pelas mulheres em nome do afeto, do dever materno e/ou da responsabilidade conjugal. Em geral, elas assumem em suas rotinas diárias uma forte carga de trabalho, em forma de cuidado, de forma gratuita, o que indica em grande medida o quanto as companheiras de presos assumem no contato com o cárcere o papel tradicional de gênero dispensado socialmente às pessoas do sexo feminino.

Há um valor simbólico em receber comida de uma fonte confiável, especialmente, durante períodos de vulnerabilidade pessoal. Esses desejos parecem se tornar mais intensos em relacionamentos rigorosamente controlados, com poucas oportunidades de manifestações de afeição e privacidade. A preparação e a partilha de comida são veículos essenciais de criação de vínculos de intimidade entre a mulher e seu companheiro preso. E também os sentimentos parecem se materializar nas comidas. A comida se torna, pois, um elo condutor na relação entre a mulher e o preso, já que funciona como uma espécie de ponte entre o mundo material e o sentimental familiar (DUARTE, 2013). Nessa mesma linha, como já mencionado, Comfort (2002) afirma que o esforço feminino acaba por tornar a prisão um "satélite doméstico": "[...] as mulheres usam a comida como uma ferramenta para 'domesticar' o ambiente carcerário" (COMFORT, 2002, p. 480).

Muitas mulheres se referiram, ainda, à dificuldade em conciliar o quotidiano profissional com a preparação para os dias de visita - tanto que algumas afirmaram ter abandonado o trabalho para encontrar regularmente o companheiro. Uma das entrevistadas atuava como auxiliar de enfermagem antes de seu marido ser condenado a cumprir oito anos de prisão. Após a imposição da reclusão, ela não conseguiu dar continuidade ao seu trabalho em decorrência da rotina de visitas, abandonando, portanto, o emprego. Esse exemplo ilustra parte importante das desigualdades às quais as mulheres estão sujeitas. Além de assumir a função de prover o sustento da família, elas também abarcam os trabalhos de cuidado familiar e de manutenção da vida doméstica. Se o "modelo de conciliação" (HIRATA; KERGOAT, 2007) já é um grande desafio às mulheres com companheiros em liberdade, esse obstáculo se potencializa no contato com o cárcere. Esses atores precisam adequar em suas rotinas tarefas como prover bens econômicos para a família, cuidar do parceiro preso, se atentar ao ambiente doméstico, acolher os filhos, entre outras atividades.

Para a entrevistada, essa equação com múltiplas variáveis se tornou insustentável. Assim, ela priorizou a visitação e o cuidado ao marido e, com isso, a manutenção das relações conjugais e familiares, em detrimento de sua vida profissional. Contou que alugou, então, um comércio próximo ao portão central do Complexo de Gericinó e nos dias de visita fechava o estabelecimento ou deixava-o sob a responsabilidade de outra pessoa para ir encontrar o marido na unidade prisional. Com a possibilidade de liberdade futura do marido, a moça pensava em fazer um concurso público na área de saúde e passar o seu ponto comercial a outra pessoa. Ou seja, buscaria retomar a vida interrompida durante o contato com o cárcere.

Eu tinha que ir visitar ele. O patrão não quer saber do seu problema. É muito difícil você encontrar um patrão que seja compreensivo. Nem compreensivo, mas humano. Que saiba compartilhar a dor de um funcionário. Infelizmente não existe isso. É muito difícil isso. (Companheira E).

Ao tratar da trajetória dos legalmente inocentes e residentes fora da prisão, mas que "vivem na sombra da prisão", Comfort (2003, p. 79) enfatiza a diminuição dos recursos materiais e a marginalização social. Esse cenário pode resultar em maior vulnerabilidade e no agravamento da situação de pobreza, além de ensejar problemas de saúde, rupturas de relações sociais e estigmatização. Em outras palavras, o encarceramento de um companheiro impacta sistematicamente o ambiente doméstico, assim como o mundo social das mulheres. No entanto, como descrito acima, em vez de camuflar um possível rótulo produzido pelo ambiente prisional, tal qual apontado por Erving Goffman (1975), a mulher o publiciza, transformando totalmente sua vida em prol da privação de liberdade de seu companheiro.

Aos olhos femininos, a prisão fez com que os presos reconhecessem o esforço das mulheres em visitá-los e, por isso, passaram a valorizá-las. Muitas entrevistadas disseram, inclusive, se sentirem em parte 'aliviadas' com a privação de liberdade do companheiro que, por estarem aprisionados, não teriam contato com outras mulheres. O cárcere estabeleceria uma espécie de 'fidelidade forçada' ao homem, mantendo-o exclusivo na relação amorosa. Não à toa, muitas apontaram que seus companheiros ficaram mais carinhosos, atenciosos e dedicados após terem sido presos. Silvestre (2012) já havia afirmado que as companheiras de presos em São Paulo costumavam 
ressaltar uma diferença entre o amor vivenciado durante a privação de liberdade de seu esposo em relação a outras experiências afetivas. Os presos teriam o "melhor amor do mundo" (SILVESTRE, 2012, p. 272).

Era mais uma questão afetiva, uma carência. Aí, aquela pessoa chega assim te dando uma proteção, te dando um carinho, você se sente protegida como mulher, aí você acaba se envolvendo. Minha questão toda, assim, foi mais essa mesmo. Acabei me apegando, me sentindo segura. (Companheira $\mathrm{E}$ ).

Nas palavras de Comfort (2007), a prisão favorece uma forma de "namoro renovado", dada a valorização do homem preso à relação com quem se esforça para manutenção desses laços através dos muros. $O$ 'cumprir pena junto' proporcionaria, portanto, sentimentos de proximidade e de parceria, a despeito da segregação e do isolamento prisional "[... ] tornando, em muitos casos, o meio correcional um instrumento regulador que - apesar de exigir um enorme sacrifício, humilhação e controle - se torna parte integrante do funcionamento das relações" (COMFORT, 2007, p. 1.056).

Dessa forma, a prisão ajudaria a reforçar relações familiares, haja vista que, entre outras situações, o local se tornaria palco do estreitamento dos laços afetivos entre o casal. Em vez de prejudicar a relação, conforme apontam diversas pesquisas no assunto (Bonnie CARLSON; Neil CERVERA, 1992; Bruce WESTERN; Sara MCLANAHAN, 2000), o contato com o cárcere poderia em algumas situações fortificá-la, ou ainda reestruturá-la. Embora estigmatizante e segregadora, a prisão não é necessariamente desestruturadora (GODOI, 2011). Nessa mesma lógica, algumas entrevistadas afirmavam que o contato com o cárcere representaria uma espécie de 'estilo de vida'. As mulheres faziam amizades com outras visitantes nas portas das prisões, marcavam de se encontrar, conversavam e trocavam experiências. Algumas ficavam amigas. Ao mesmo tempo que podia gerar consequências negativas às suas vidas, o sistema penitenciário acarretava efeitos benéficos a algumas companheiras de presos, como agregar pessoas.

Ao descrever uma série de interações familiares e sociais decorrentes da visita a pessoas privadas de liberdade, Comfort (2002) ressalta os processos emocionais e institucionais contraditórios que complicam e reformulam as relações durante o período de encarceramento. No esforço feminino de tentar evitar a institucionalização de seus companheiros, dando apoio emocional e mantendo sua conexão com o mundo externo, a prisão passa a ser uma alternativa à vida privada, absorvendo as relações familiares e sociais. Não obstante, há casos de mulheres que conheceram seus companheiros na prisão através de uma amiga, de algum trabalho religioso, de carta etc. Algumas não sabiam como os companheiros se portavam do 'lado de fora', pois apenas tinham tido contato com eles no cárcere. Há também relatos sobre pessoas que se separavam dos parceiros recém-saídos em liberdade e logo passavam a se relacionar com algum outro interno que conheceram nos dias de visita à prisão. O sistema penitenciário se entranha, assim, ao cotidiano e à identidade de algumas visitantes.

Como eu exercia uma função eclesiástica no ministério, naquele ministério de Madureira, aí eu fazia alguns trabalhos mesmo na comunidade, e acabei conhecendo a mãe dele ldo companheiro), que era alcoólatra, ajudando. E ela sempre pedia pra eu poder manter um contato com ele, por causa da situação financeira dela, ela não tinha como. Ela não tinha como visitá-lo, não tinha como nada. Aí, passamos a ajudá-la enviando alguns recursos pra ela poder ir pra visita, tal, e acabei me aproximando dele. Foi quando realmente começamos, com uma amizade. Eu comecei ajudando de alguma forma, às vezes aconselhando a seguir um outro caminho, uma outra opção de vida. Ajudando a falar com os filhos, que ele não tinha contato já há quatro anos. [...] Aí eu decidi: vamos radicalizar minha vida, porque era uma coisa que eu nunca tinha me envolvido, era um contato que eu nunca tinha tido, eram lugares que eu nunca pensei que eu fosse frequentar. Depois que eu conheci, frequentei, visitei. Eu não faltava a uma visita, era chuva ou sol. Eu estava lá. (Companheira E).

A experiência com o sistema prisional pode se tornar, pois, quase como algo expansivo, como um meio de transformação de vida. Talvez por isso muitas mulheres contatadas tenham se mostrado à vontade em manter relações sexuais com o companheiro em uma prisão. No entanto, ainda que tenham sido levantados dados com tal teor, esse ponto não foi pacífico entre todas as informantes. Algumas, por exemplo, resolveram esperar a liberdade do parceiro para voltarem a fazer sexo. Geralmente, nesses casos em que foi estabelecida uma espécie de abstinência forçada, os presos tinham sido condenados a penas mais curtas e, por isso, possuíam a perspectiva de sair mais rápido da prisão. Em outras situações, as mulheres apresentavam discursos imbuídos de elementos religiosos, saturados de deduções morais.

De fato, a intimidade feminina é violada em diferentes momentos nos dias de visita, sendo, por exemplo, as revistas corporais e as rígidas regras de conduta impostas aos visitantes percebidas como transgressoras. Para essas situações, elas não pareciam possuir muita margem de barganha: ou as mulheres vão às visitas, respeitam as regras e mantêm a relação com o parceiro preso; ou elas deixam de visitar os companheiros e rompem a relação. Contudo, ao que parece, em alguma 
medida certas mulheres tinham a opção de realizar ou não a visita íntima. Essa questão era posta em discussão entre o casal e, ao menos em alguns casos, os homens aceitavam a posição das mulheres em não fazer sexo na prisão.

Daí a situação peculiar enfrentada pelas mulheres que lutam contra a 'institucionalização' de seus companheiros: através de seus esforços para criar fortes laços inclusivos com o parceiro encarcerado, elas participam da 'institucionalização' paradoxal de sua própria vida familiar e assim estendem o alcance e a intensidade dos efeitos transformadores do aparelho carcerário (COMFORT, 2002, p. 471).

\section{Relacionamento 'chave de cadeia'}

As seções acima mostram que as mulheres em relacionamentos com homens em privação de liberdade mudam suas rotinas diárias, se sujeitam a regras e aderem ao controle do espaço prisional, ainda que em muitos casos apresentem uma experiência positiva no contato com o cárcere. Nesse contexto, oferecem apoio emocional e material abundantes, bem como se esforçam para assegurar algum nível de interlocução entre os companheiros presos e a vida externa ao cárcere, transferindo atividades privadas, típicas da esfera doméstica, ao mundo prisional. Mas, quais são as dinâmicas imbuídas nos relacionamentos denominados no senso comum de 'chaves de cadeia'? As mulheres desempenham papéis relacionados tão somente ao cuidado de seus companheiros, tal como posto pelas expectativas de gênero que constroem e reafirmam a divisão sexual do trabalho tradicional?

Boa parte das entrevistadas disse conhecer as atividades ilegais exercidas pelos companheiros antes do encarceramento. Não necessariamente apoiavam, mas compreendiam o tipo de vida que eles levavam. Algumas mulheres chegaram a romper com a família ou a esconder dos pais e amigos o envolvimento do esposo em dinâmicas criminais.

Meu pai não. Eu ia escondida. Depois, quando meu pai descobriu, aí eu falei assim 'não posso mais esconder, tenho que falar...'. Aí, depois, meu pai ficou falando: 'Você vai visitar ele? O que é que tem? Ele que pediu pra ser preso, você não tem que fazer nada lá'. Eu falei pra ele: 'não, eu não quero nada disso, não'. Eu ia e ele falava, mas eu já era de maior. Ele não podia me falar mais nada. Aí, depois ele largou de mão e deixou. (Companheira F).

Por certo, durante as entrevistas, algumas mulheres não costumavam expor deliberadamente por qual conduta o parceiro havia sido preso e condenado, mas forneciam juízos de valor geralmente negativos sobre os atos realizados. Afirmavam que seus companheiros não 'precisavam' ter se envolvido no 'mundo do crime', pois possuíam recursos financeiros necessários para custear uma 'vida digna'. Nessa lógica, surgiram diversos discursos cujo objetivo era em alguma medida neutralizar as ações masculinas. Isto é, as mulheres diziam que o parceiro seria 'influenciável'; ele seguiu o caminho de amigos que seriam 'más companhias'; ele só tinha 'errado' uma única vez, a prisão não era local 'adequado' ao companheiro etc. As mulheres eximiam, então, seus parceiros de parte da responsabilidade sobre o crime realizado por um elemento externo ter exercido influência sobre eles.

Eu ainda falava pra ele assim 'não sei o que você está fazendo aí dentro, isso aí não é lugar pra você...', porque ele sempre foi uma pessoa que sempre trabalhou, sempre trabalhava, não sei por que... Haja explicação... Seguiu, foi pro caminho do crime, foi traficar, foi ser gerente de tráfico e aconteceu o que aconteceu, veio pegar logo seis anos de cadeia. (Companheira D).

Esses discursos voltados à tentativa de relativizar as atividades dos parceiros vão ao encontro do que afirma Comfort (2007) sobre o esforço de as mulheres energicamente atenuarem as privações e os rótulos dos homens submetidos à privação de liberdade.

Me dá pena. Muito mais porque eu acho que é muita sacanagem o que está acontecendo. Porque a situação dele, na minha opinião, é injusta. Porque, realmente, ele é uma pessoa que participou de um crime, participou de um crime, mas não era o mentor, não era da parte mais alta da cadeia. Teve um monte de gente que, realmente... Tipo assim, um monte de gente já saiu da história, já não está mais preso. E ele, que é um 'merda', porque foi um trouxa, continua preso porque não tem dinheiro, porque a gente não tem grana pra tirar. Entendeu? (Companheira C).

Entretanto, algumas mulheres percebiam o crime como 'natural', chegando a participar da rotina de ilegalismos do companheiro. Esse aspecto foi em boa medida negligenciado pela literatura especializada, pois quase não se menciona que as companheiras de presos podem ter agência na execução do crime e no desempenho de funções que ultrapassam o cuidado com a pessoa privada de liberdade. Portanto, não é exagero sugerir que as mulheres de presos desempenham diversas funções, algumas das quais aquém das estipuladas pelos papéis tradicionais de gênero. Como destacam Hirata e Kergoat (2007), atentar-se às novas configurações da divisão sexual do trabalho é considerar as condições e a plasticidade das relações sociais de 
sexo. Separados pelos muros das prisões, a agência feminina se transforma em decorrência não só das condições impostas pelo cumprimento da pena, mas também pela proximidade com o mundo do crime.

No trecho a seguir, a entrevistada relata que o contato com certas ações ilegais se tornou tão comum em sua rotina que ela não vislumbrava a possibilidade de seu esposo ser preso. Na sua perspectiva, enquanto possuísse dinheiro e certo prestígio no local onde atuava, o marido se manteria impune. Porém, essa visão se mostrou bastante frágil quando o parceiro foi efetivamente flagrado e condenado pelo sistema de justiça.

Eu comecei a ter contato com o mundo do crime realmente, de eu ver as coisas erradas que ele fazia, de estar ali perto da contabilidade de favela, de como a favela anda ou deixa de andar, essas coisas, que eu estava do lado dele e acabava ouvindo e acompanhando algumas coisas, foi ali que eu fui vendo. $E$ as vezes que ele foi preso, ele foi preso, mas pagou e saiu. Então, eu achava o seguinte: enquanto ele tiver dinheiro, ele jamais vai ficar preso. Só que chegou um momento em que realmente foi preso e ficou preso. Não tinha ficha, não teve dinheiro, não teve nada, ele foi preso e acabou. [...] E comecei a visitar. Que ele estava preso e eu vi realmente que não ia sair. $E$ os processos que ele respondeu, que ele fugiu, ele foi sentenciado, aí pegou vinte e um anos. Antes disso, ele ainda conversou: 'realmente, você vai querer ficar comigo? É isso que você quer? Estou com vários problemas...', 'Não, não. É isso que eu quero...' e comecei a visitar. (Companheira B).

Mesmo após a prisão do marido, a mulher entrevistada permaneceu envolvida com atividades do tráfico de drogas. Em consequência, tempos depois foi pega pela polícia, recebendo em seguida uma condenação. Ao término de sua privação de liberdade, ela afirmou ter compreendido que aquele tipo de 'vida' era 'errado' e, desse modo, decidiu se desvincular das ações criminosas. O 'mundo' tinha 'caído' com a prisão.

Ele já preso, nesse período de onze anos que ele está preso até hoje. Em 2007 eu entrei numa escuta telefônica, quebraram meu sigilo bancário também e... Fui presa. Invadiram minha casa e era um processo com dezesseis pessoas, então todo mundo com quem nós falamos, com quem eu fiz a movimentação financeira, todo mundo foi preso. [... Aí meu mundo desabou. Foi a pior... Acho que uma das piores experiências que eu tive na minha vida. Aí, fiquei três anos presa, fui sentenciada a oito, por extorsão, formação de quadrilha, associação ao tráfico e financiar e custear o tráfico. Alguns eu fui absolvida, mas no total deram oito anos. Aí, eu fiquei três anos presa e saí de condicional, que eu estou de condicional até hoje. E, ali eu amadureci. Ali foi onde a ficha caiu, que eu vi que se eu pudesse voltar atrás, eu tinha mudado a minha vida toda e não tinha feito metade das besteiras que eu fiz, em relação a tudo. (Companheira B).

Enquanto esteve presa, a mulher (acima) e seu companheiro trocaram cartas e depois de um ano passaram a realizar a visitação entre cônjuges, mantendo contato. Ela cumpriu cerca de três anos em regime fechado e, quando alcançou a liberdade, começou a trabalhar em um escritório e manteve as visitas ao marido ainda em privação de liberdade.

Eu falei pra ele: 'vamos trabalhar, vou levar outro ritmo de vida, não vou ficar mais nessa vida. Estou completamente envolvida nesse seu mundo e não vou, não vou. Vou levar minha vida. Não estou me separando, o que eu sinto por você não mudou, mas eu tenho que dar outro seguimento. A gente tem um filho, eu não posso ficar mais...', eu vou estar vivendo a mesma vida que a dele, sempre na cadeia. Ele ficou meio... 'como é que eu vou ficar, você vai começar a trabalhar, não vai conseguir trabalhar...', eu falei: 'eu vou conseguir trabalhar, não tem porque eu não conseguir'. Aí ele 'ah, mas você não vai vir me visitar...', eu falei 'não, eu vou conciliar tudo, trabalhar, vir te visitar, você não vai ficar sem visita, eu vou estar aqui sempre, final de semana eu vou vir'. E é o que eu estou fazendo agora. (Companheira B).

O seu 'esforço' em realizar as visitas, embora estivesse em liberdade, foi utilizado como 'moeda de troca' com o companheiro. Ou seja, a contrapartida de muitas mulheres em se devotar ao parceiro durante o encarceramento seria que ele deixasse de exercer atividades ilegais ao ser posto em liberdade. Não à toa, alguns meses após a realização da entrevista que produziu os trechos de narrativa expostos acima, manteve-se um novo contato com a mulher. Ela afirmou ter se separado, pois, ao progredir de pena para o regime semiaberto, o marido teria retomado o envolvimento com o tráfico de drogas. De acordo com a entrevistada, ela não poderia mais se relacionar com uma pessoa não disposta a 'mudar de vida' e a 'sair do crime'.

Sendo a divisão sexual do trabalho uma dinâmica social que se transforma a depender do tempo e do espaço, as companheiras dos presos trazem novas configurações possíveis para este conceito e até mesmo novas estratégias que tensionam as relações entre mulheres e homens privados de liberdade. No cárcere, o amor muitas vezes é traduzido no cuidado e no apoio da companheira ao preso. Mas, para além disso, os papéis desempenhados pelas mulheres que mantêm relação com homens custodiados podem incluir tanto a agência feminina na vida criminosa, quanto a agência da mulher na imposição de condicionantes à manutenção dos 
laços afetivos. Algumas companheiras de egressos do sistema prisional comentavam orgulhosas sobre o parceiro ter recusado diversos convites para voltar a cometer crimes, como tráfico de drogas e roubos. O esforço delas durante a privação de liberdade do companheiro parecia ter sido recompensado. 'Valeu a pena' passar por alguns dos transtornos causados pelo contato com a prisão. Muitas mulheres costumavam se analisar, então, como uma espécie de conexão emocional e doméstica ao cárcere, cuja função seria a transição do preso ao 'mundo livre'. Elas se percebiam como 'pontes para ressocialização', tal como indicado por Silvestre (2012) em relação às mulheres que visitavam seus parceiros em um complexo prisional paulista.

Em contrapartida, ainda que tenha 'valido a pena', os esforços despendidos para a não reinserção do companheiro no crime são desgastantes para as mulheres. E esse esgotamento pode se perpetuar mesmo após a conquista da liberdade do parceiro. Uma das entrevistadas mencionou que se sentia como uma 'nuvem' perto do companheiro recém-saído da prisão, pois precisava 'amortecer' boa parte de seus atos. Segundo ela, o marido havia se desacostumado com o dia a dia em liberdade e, por isso, ela quase que o 'reensinava' a viver. Se dentro da prisão o homem era um grande líder respeitado por todos os presos, fora se tornou um 'sujeito comum', sem regalias ou prestígio. Esse contexto ensejava forte frustração, sentimento que em boa medida passou a ser administrado sistematicamente pela mulher.

\section{Considerações finais}

A proposta deste artigo foi analisar a perspectiva de companheiras de presos, com vistas a compreender os diferentes papéis que desempenham no mundo carcerário. Fez-se uso, então, de dados colhidos via entrevistas semiestruturadas com mulheres que visitam seus companheiros custodiados no sistema prisional do estado do Rio de Janeiro. Por certo, as análises partiram de duas premissas complementares entre si: por um lado, vislumbrou-se existir uma manutenção da tradicional divisão sexual do trabalho no mundo intramuros, condicionada pelas relações de gênero, em que as mulheres assumem o cuidado doméstico e afetivo durante o encarceramento de seu companheiro; por outro, ao entrar nessa dinâmica, as mulheres sofrem uma variante da prisionização, chamado por Comfort de "prisionização secundária". Porém, a despeito dessas hipóteses, os dados verificados permitiram depreender algumas observações que devem ser cuidadosamente colocadas.

Ao decidir levar a vida doméstica à prisão na tentativa de neutralizar a institucionalização do preso, muitas mulheres passam por um processo de interiorização de normas e regras do sistema carcerário, vivenciando o já dito processo de prisionização. Isso ocorre muitas vezes porque, ou essas mulheres aceitam as condições estruturais a elas impostas e, assim, mantêm o contato com o parceiro, ou rompem suas relações afetivas. Desse modo, se sujeitam a uma série de regras legais, extralegais e, em alguns casos, ilegais, subordinando-se, assim, a normas que estipulam desde o modo como devem se vestir nos dias de visita até a forma como devem olhar as outras pessoas nas unidades prisionais. As companheiras se esforçam, pois, para dar continuidade ao laço afetivo com o preso ao realizar não apenas sistematicamente as visitas, como também ao entregar as 'sucatas', ao manter encontros sexuais no cárcere, ao respeitar as regras da cadeia etc. À primeira vista, é possível pensar que tais práticas seriam frutos tão somente da tradicional divisão sexual do trabalho, em que as mulheres se responsabilizam pelo cuidado de seu companheiro, dada a desigual relação social de gênero.

Entretanto, conforme as análises desenvolvidas, o contato com o cárcere pode ser também algo transformador, tensionador e reestruturador de relações. Não obstante, relatou-se a capacidade de escolha da mulher no que tange à realização da visita íntima. Adicionalmente, algumas narrativas femininas ressaltaram o contato com o cárcere para barganhar mudanças de vida do companheiro. Muitas mulheres optaram ainda por realizar as visitas por se sentirem mais valorizadas e receberem maior carinho dos homens privados de liberdade. Por sua vez, há aquelas que intencionalmente embarcam em um amor 'chave de cadeia' por se sentirem prestigiadas e fortes ao se colocarem em contato com dinâmicas criminais.

Portanto, são vários os papéis desempenhados por mulheres que optam por 'cumprir pena junto' com companheiros encarcerados, sendo obtuso reduzir suas ações apenas à tradicional divisão sexual do trabalho. Ainda que assumam o papel de cuidado e de apoio abundante durante a privação de liberdade, as mulheres desempenham atividades adicionais, muitas das quais percebidas, por elas, como emancipadoras e constituidoras de novas identidades.

\section{Referências bibliográficas}

APFELBAUM, Erika. "Dominação". In: HIRATA, Helena; LABORIE, Françoise; DOARÉ, Hélène Le; SENOTIER, Danièle (Orgs.). Dicionário crítico do feminismo. São Paulo: UNESP, 2009. p. 76-96.

BRASIL. Ministério da Justiça. Conselho Nacional de Política Nacional e Penitenciária (CNPCP). Resolução CNPCP n 4, de 29 de junho de 2011 . Recomenda aos Departamentos Penitenciários 
Estaduais ou órgãos congêneres seja assegurado o direito à visita íntima a pessoa presa, recolhida nos estabelecimentos prisionais. Diário Oficial da União, Brasília, jun. 201 1. Disponível em: https:// direito.mppr.mp.br/arquivos/File/Resolucao04_201 1 Recomenda.pdf. Acesso em 04/09/2020.

CARLSON, Bonnie; CERVERA, Neil. Inmates and their wives: incarceration and family life. Westport: Greenwood, 1992.

CLEMMER, Donald. "Observations on imprisonment as a source of criminality". Journal of Criminal Law \& Criminology, v. 41, n. 3, p. 311-319, 1950. Disponível em https://scholarlycommons.law.northwes tern.edu/cgi/viewcontent.cgi?article=3795\&context=jclc Acesso em 04/09/2020.

COMFORT, Megan. "'Papa's House': the prison as domestic and social satellite". Ethnography, v. 3, n. 4, p. 467-499, Dec. 2002. https://doi.org/10.1177/1466138102003004017.

COMFORT, Megan. "In the tube at San Quentin: the 'secondary prisonization' of women visiting inmates". Journal of Contemporary Ethnography, v. 32, n. 1, p. 77-107, Feb. 2003. https://doi.org/ $10.1177 / 0891241602238939$.

COMFORT, Megan. "'Partilihamos tudo o que podemos': a dualização do corpo recluso nos romances através das grades". Análise Social, v. 42, n. 185, p. 1.055-1.079, 2007. Disponível em http:// www.scielo.mec.pt/pdf/aso/n185/n185a06.pdf. Acesso em 02/09/2020.

CUNHA, Manuela Ivone. "Etnografias da prisão: novas direções". Revista de Sociologia: Configurações, n. 13, p. 47-68, 2014. Disponível em https://journals.openedition.org/configuracoes/ 2389. Acesso em 02/09/2020.

CUNHA, Manuela Ivone. "O bairro e a prisão: a erosão de uma fronteira". In: BRANCO, Jorge Freitas; AFONSO, Ana Isabel (Orgs.). Retóricas sem fronteiras. Lisboa: Celta, 2003. p. 101-109.

DEVREUX, Anne-Marie. "Família". In: HIRATA, Helena; LABORIE, Françoise; DOARÉ, Hélène Le; SENOTIER, Danièle (Orgs.). Dicionário crítico do feminismo. São Paulo: UNESP, 2009. p. 96-101.

DUARTE, Thais Lemos. Amor em cárcere: relações afetivas no sistema penitenciário do Rio de Janeiro. 2015. Doutorado (Programa de Pós-Graduação em Ciências Sociais) - Instituto de Filosofia e Ciências Humanas, Universidade do Estado do Rio de Janeiro, Rio de Janeiro, RJ, Brasil.

DUARTE, Thais Lemos. "Amor, fidelidade e compaixão: 'sucata' para os presos". Sociologia \& Antropologia, v. 3, n. 6, p. 621-641, nov. 2013. Disponível em http://www.scielo.br/pdf/sant/v3n6/ 2238-3875-sant-03-06-0621.pdf. Acesso em 04/09/2020.

GODOI, Rafael. "Para uma reflexão sobre os efeitos sociais do encarceramento". Revista Brasileira de Segurança Pública, São Paulo, ano 5, ed. 8, p. 138-154, fev./mar. 2011. Disponível em http:// www.susepe.rs.gov.br/upload/20121206161416artigo_efeitos_sociais_do_encarceramento\%5B1\% 5D.pdf. Acesso em 02/09/2020.

GOFFMAN, Erving. Estigma: notas sobre a manipulação da identidade deteriorada. Rio de Janeiro: LTC, 1975.

HIRATA, Helena; KERGOAT, Danièle. "Novas configurações da divisão sexual do trabalho". Cadernos de Pesquisa, v. 37, n. 132, p. 595-609, set./dez. 2007. Disponível em http://www.scielo.br/pdf/cp/ v37n132/a0537132.pdf. Acesso em 04/09/2020.

JARDIM, Ana Caroline Montezano Gonsales. Famílias e prisões: (sobre)vivências de tratamento penal. 2010. Mestrado (Programa de Pós-Graduação em Serviço Social) - Pontifícia Universidade Católica do Rio Grande do Sul, Porto Alegre, RS, Brasil.

KERGOAT, Danièle. "Divisão sexual do trabalho e relações sociais de sexo". In: HIRATA, Helena; LABORIE, Françoise; DOARÉ, Hélène; SENOTIER, Danièle. Dicionário crítico do feminismo. São Paulo: Unesp, 2009. p. 67-75.

KUHN, Claudia. Reflexões sobre o processo de prisão e as consequências nas condições socioeconômicas para familiares de presos da Penitenciária Estadual de Francisco Beltrão/PR. 2016. Mestrado (Programa de Pós-Graduação em Serviço Social) - Universidade Estadual do Oeste do Paraná, Toledo, PR, Brasil.

LEMGRUBER, Julita. Cemitério dos vivos: análise sociológica de uma prisão de mulheres. 2. ed., Rio de Janeiro: Forense, 1999. 
LIMA, Jacqueline Stefanny Ferraz de. Mulher fiel: as famílias das mulheres de presos relacionados ao Primeiro Comando da Capital. 2013. Mestrado (Programa de Pós-Graduação em Antropologia Social) - Universidade Federal de São Carlos, São Carlos, SP, Brasil.

MAGALHÃES, Carlos Augusto Teixeira. O crime segundo o criminoso: um estudo de relatos sobre a experiência da sujeição criminal. 2006. Doutorado (Programa de Pós-Graduação em Sociologia e Antropologia) - Universidade Federal do Rio de Janeiro, Rio de Janeiro, RJ, Brasil.

PAIXÃO, Antônio Luiz. Recuperar ou punir? Como o Estado trata o criminoso. São Paulo: Cortez Autores Associados, 1987.

SAFFIOTI, Heleieth. Gênero, patriarcado, violência. São Paulo: Editora Fundação Perseu Abramo, 2004.

SCOTT, Joan. "Gênero: uma categoria útil de análise histórica". Educação e Realidade, v. 20, n. 2, p. 71-99, 1995. Disponível em https://seer.ufrgs.br/educacaoerealidade/article/view/71721/ 40667. Acesso em 02/09/2020.

SILVESTRE, Giane. Dias de visita: uma sociologia da punição e das prisões. São Paulo: Alameda, 2012.

SOUZA, Luana Passos de; GUEDES, Dyego Rocha. "A desigual divisão sexual do trabalho: um olhar sobre a última década". Estudos Avançados, v. 30, n. 87, p. 123-139, 2016. Disponível em http:/ /www.scielo.br/pdf/ea/v30n87/0103-4014-ea-30-87-00123.pdf. Acesso em 04/09/2020.

SYKES, Gresham. The society of captives: a study of a maximum security prison. New Jersey: Princeton University Press, 1999.

THOMPSON, Augusto. A questão penitenciária. 4. ed. Rio de Janeiro: Forense, 1993.

WESTERN, Bruce; MCLANAHAN, Sara. "Fathers behind bars: the impact of incarceration on family formation". Contemporary Perspectives in Family Research, v. 2, Jan. 2000.

Thais Lemos Duarte (thais-duarte@hotmail.com) é pesquisadora de pós-doutorado no Programa de Pós-Graduação em Sociologia da Universidade Federal de Minas Gerais (PPGS/ UFMG), bolsista do CNPq. Doutora em Ciências Sociais pelo Programa de Pós-Graduação em Ciências Sociais da Universidade do Estado do Rio de Janeiro (UERJ), mestre pelo Programa de PósGraduação em Sociologia e Antropologia da Universidade Federal do Rio de Janeiro (PPGSA/UFRJ) e bacharela em Ciências Sociais pela UERJ.

Luana Hordones Chaves (luanahordones@ufmg.br) é pós-doutoranda no Programa de Pós-Graduação em Sociologia (PPGS) e pesquisadora do Centro de Estudos em Criminalidade e Segurança Pública (CRISP), ambos da Universidade Federal de Minas Gerais. Doutora em Sociologia pela UFMG, mestre em Ciências Sociais e bacharela em Relações Internacionais pela Universidade Estadual Paulista (UNESP).

Isabela Cristina Alves de Araújo (isabelaaraujo@estudante.ufscar.br) é doutoranda em Sociologia pela Universidade Federal de São Carlos (UFSCar), mestre em Sociologia e bacharela em Ciências Sociais pela Universidade Federal de Minas Gerais (UFMG). Pesquisadora do Centro de Estudos em Criminalidade e Segurança Pública (CRISP) da UFMG, participa de pesquisas voltadas para a realidade do sistema prisional, agentes prisionais, mulher em situação carcerária e organizações criminais. 


\section{COMO CITAR ESSE ARTIGO DE ACORDO COM AS NORMAS DA REVISTA}

DUARTE, Thais Lemos; CHAVES, Luana Hordones; ARAÚJO, Isabela Cristina Alves de. "Cumprindo pena juntos". Revista Estudos Feministas, Florianópolis, v. 28, n. 3, e60699, 2020.

\section{CONTRIBUIÇÃO DE AUTORIA}

Thais Lemos Duarte: Coleta de dados e análise de dados, revisão bibliográfica, redação do texto final, discussão de resultados.

Luana Hordones Chaves: Revisão bibliográfica, análise de dados, redação do texto final, discussão de resultados.

Isabela Cristina Alves de Araújo: Revisão bibliográfica, análise de dados, redação do texto final, discussão de resultados.

\section{FINANCIAMENTO}

O presente trabalho foi realizado com apoio da Coordenação de Aperfeiçoamento de Pessoal de Nível Superior (CAPES). A pesquisa de doutorado que deu origem ao presente artigo foi realizada com apoio do CNPq.

\section{CONSENTIMENTO DE USO DE IMAGEM}

Não se aplica.

APROVAÇÃO DE COMITÊ DE ÉTICA EM PESQUISA

Não se aplica.

CONFLITO DE INTERESSES

Não se aplica.

LICENÇA DE USO

Este artigo está licenciado sob a Licença Creative Commons CC-BY International. Com essa licença você pode compartilhar, adaptar, criar para qualquer fim, desde que atribua a autoria da obra.

\section{HISTÓRICO}

Recebido em 16/12/2018

Reapresentado em 05/02/2020

Aprovado em 07/04/2020 